\title{
The most important aspects of early foreign-language education in primary schools
}

\author{
Anvar N. Khuziakhmetov - Agzam A. Valeev - Zdena Kralova - Jana \\ Duchovicova
}

DOI: 10.18355/XL.2018.11.02.30

\begin{abstract}
Currently, the problem of early foreign-language education in the conditions of primary school is becoming more urgent, which causes a natural controversy among educators, psychologists, and methodologists; it is facilitated by the fact that a foreign language creates excellent opportunities for awakening interest in the linguistic and cultural diversity of the world, respect for languages and cultures of other nations. Moreover, a foreign language is now a common practice, as training is determined by the needs of society, which is interested in foreign-language literacy of Russian citizens, representing a worthy image of a Russian abroad while strengthening international relations. All this proves the urgency of mastering a foreign language at an early age and requires the search for effective ways to improve the teaching methodology. The article reveals the following aspects: The importance of the problem of organizing early foreign-language education; Features and advantages of early foreign-language education; Organization of early foreign-language education in a functional context; Possibility of improving the skills of foreign speech activity in the conditions of early foreign-language education. Thus, the study showed the importance of the problem of early foreign language education that allows a new view at the problems of intellectual development of primary school students.
\end{abstract}

Key words: foreign language, primary school, junior schoolchild, foreign language education, educational process, foreign language activity, educational activity, educational functions, teaching technologies, foreign language communication

\section{Introduction}

\subsection{Actualizing the problem}

The process of Russia's entry into the world community poses the problem of a good command of a foreign language at one of the first places in the education system. Against this background, there is a clear increase in the interest in foreign languages. To a large extent this interest is of a purely pragmatic nature, reflecting the need for an adequate knowledge of foreign languages, without which one cannot count on the professional and vital success of a single individual. Hence, the interest of the state becomes clear, as is the interest of parents in the problem of teaching foreign languages, starting from the first years of schooling. In this regard, the great changes taking place in Russia have determined the need to learn foreign languages, so schools of different types have started to appear-gymnasiums, lyceums, author's schools, etc. And in the new programs for teaching a foreign language, the main strategy of education is offered - the formation of a fully developed personality based on the Europeanization of education through a dialogue of cultures and civilizations of the modern world.

The analysis of the educational situation in this area allows us to identify the following main trends in the development of modern foreign language education in the primary school of the Russian Federation:

- Foreign-language education in primary school became recognized as a value at all levels (state, public and personal) and be considered as an important mechanism for building the future successful life of the student and his mobility in a multicultural and multilingual world; 
- The linguistic and cultural diversity of Russia in itself is a fruitful basis for the development of the multilingualism of the individual, starting with the primary school;

- Foreign-language education contributes to the integration of the national secondary school in the European and global educational space (for example, the development of the Russian version of the document "European Language Portfolio" for children 7-10 years in relation to the conditions of Russia);

- The modern elementary school includes different variants of foreign language education, which have distinctive features related to the chosen model of the educational process (various teaching and methodological complexes realize different views on the teaching of a foreign language depending on what goals are put forward in this school).

As for the type of primary school where foreign language training is provided, in Russia they are represented as follows: Primary school in a mass general education school; Progymnasium as an independent educational institution; Primary school as the first stage of an elite school for gifted and capable children; Primary school as the first stage of the school of in-depth development of children in the field of any cycle of academic disciplines. Thus, according to the Concept of the content of general secondary education, starting from the second grade of the primary school, the study of the English language is introduced.

The new basic curriculum provides for the compulsory study of a foreign language from II to IV grade in an elementary school at 2 hours a week with its compulsory study at the main and senior levels of study. Proceeding from this, the principle of continuous language school education in the field of studying foreign languages is realized, which corresponds to the modern needs of the individual and society. In this connection, it becomes necessary to pay special attention to modern and effective technologies for teaching a foreign language, especially taking into account the personality-oriented methodology and age characteristics of children of primary school age (Lomakina, 2014).

\subsection{The study of the problem of organizing early foreign language education in the national school}

The issues related to teaching a foreign language of junior schoolchildren are now the subject of wide discussions since this age is considered by specialists as the most favorable period for mastering a foreign language (Galskova, 1990; Vereshchagina \& Rogova, 1998). In this regard, the teaching of English language students pursues a comprehensive implementation of practical, educational, general educational and developmental goals. Thus, a foreign language contributes to the formation of a fully developed personality which is the main task of the school at the present stage of the formation of our society. The study of the problem of organizing early foreign language education is related to the following tasks: The formation and development of foreign phonetic skills (based on the mechanisms of mastering native speech, when the speech device is flexible and phonetic skills are easily assimilated); Development of listening skills (understanding of speech by ear); Development of speaking skills (that is, forming a child's notion of a foreign language as a means of communication); Formation and replenishment of lexical stock. The fact that (with the modernization of the Russian educational system) a foreign language is proposed to be taught already from the primary school is a recognition of the social interest in the study of foreign languages and proving the importance of the subject for the realization of the longterm objectives of the diversified development of the individual. Moreover, the study of a foreign language at a younger school age is beneficial to all children, regardless of their starting abilities, since it contributes to the following: A positive influence on the development of the child's mental functions (memory, attention, thinking,

XLinguae, Volume 11, Issue 2, April 2018, ISSN 1337-8384, eISSN 2453-711X 
perception, imagination); This stimulates the impact on the general speech abilities of the child; This creates a great practical effect in terms of improving the quality of cognitive activity of schoolchildren as a whole. As practice shows, early instruction in a foreign language is important because the success in mastering the subject at the next steps depends on how the training is going on at the initial stage. Thus, the English methodologist H.E. Palmer (1923) attached great importance to the beginning of the study of a foreign language: «Take care of the first two stages, and the rest will take care of itself». It is at the initial stage that a methodical system is put in place, which is the basis for teaching a foreign language.

\subsection{Features of Early Foreign Language Education}

The peculiarities of early foreign language education are due to the fact that the very educational function of a foreign language (for example, English) is great, since it helps to expand the students' philological outlook, general outlook and, on this basis, increase knowledge about the culture of peoples, history, art of English speaking countries. And the difficulty of mastering a foreign language in an elementary school is that an interrelated development of a foreign language with the educational activities of its realizing is necessary. This applies, in particular, to such abilities as cognitive ability and speech ability for speaking activity in another language. It is these abilities that can be considered the basis for the development of a junior schoolchild and the formation of his ability to communicate in a foreign language within the framework of a dialogue of cultures, which is one of the most important goals of foreign-language education in primary school. And the specificity of the age of the junior schoolchild is such that the success of his mastery of a new language is determined by the success of the actual learning activity. This feature, related to the initial foreign language education, includes such aspects as: Development: development and self-development of the personality of the junior schoolchild and a complex of his abilities and readiness for using a foreign language as a means of intercultural communication; Upbringing: moral development and self-development of a junior schoolchild in the process of studying non-native languages and cultures; Teaching (i.e., learning activity): the knowledge of the junior schoolchildren of linguistic means and culture of the country of the studied language, and hence the mastery of foreign speech activity as a new way of intercultural communication. Proceeding from this, the theory of teaching foreign languages in an elementary school includes three components:

- Linguistic component: It integrates linguistic and speech material, including sociocultural and regional studies aspects (involves learning in sequence from speech to language as the social rules of its functioning on the basis of the provisions of social and functional linguistics);

- Psychological component: It includes the formed skills and abilities that provide students with the use of the language for communication purposes (assumes specific actions and operations that ensure the operation of appropriate speech mechanisms responsible for listening, speaking, reading, writing);

- Methodical component: It is connected with mastering the methods of teaching (it presupposes the formation of rational methods of teaching based on the analysis of the language, skills, and abilities of working with the teaching material, mastering the rules for the performance of tasks).

Therefore, in the process of teaching a foreign language students develop such skills as: The ability to listen to a teacher and an interlocutor; The skill of working in different modes (individually, in pairs, front, in a group), interacting with each other; The skill to control and evaluate speech actions both of one's own and of comrades; The ability to observe this or that linguistic phenomenon in the teacher's perceived speech; The ability to compare and contrast the linguistic phenomenon in a foreign language and in the native language; The ability to recognize and differentiate 
language phenomena and words in a foreign language (for example, proper names, words denoting objects, actions, etc.); The ability to distinguish the main thing when hearing a speech utterance, etc.

\subsection{Status of a Problem}

Based on the relationship of linguistics, psychology, and didactics with the methodology, this problem is analyzed in the works of M.N. Vyatyutnev (1990), A.A. Valeev, N.M. Muzafarova (2016), N.A. Gorlova (2010). The conceptual basis for the study of the educational environment in teaching junior schoolchildren is considered in the works of Z.N. Nikitenko (2008), E.G. Ivanova (2003), E.I. Negnevitskaya (1987), R.R. Nasibullov, I.A. Neyasova, V.K. Adilova (2016). A significant contribution to the development of the theory and methodology of early foreignlanguage learning was made by I.N. Vereshchagina, G.V. Rogova (1998), S.V. Logunova (1997), O.A. Denisenko (1995). The problems of increasing the efficiency of foreign language education were studied in the works of I.A. Grishanova (2007), A.A. Pligin (2008), N.V. Elukhina (1986). A great contribution to the study of the psychological and linguistic features associated with foreign-language instruction was made by such scientists as M.G. Kasparova (1986) A.O. Pirozhkova (2014), A.V. Shafikova (1998). Applied to the teaching of the second language this problem was studied by the methodologists M.Z. Biboletova (1985), E.I. Negnevitskaya (1996), V.S. Korostelev (1992). The analysis of the features of foreign-language instruction was conducted by M.M. Bezrukih (2009), N.D. Gal'skova (1990), L.A. Tsyban (2017). Questions of the personification of foreign language education were studied by A.V. Barannikov (2002), G.R. Lomakina (2014), I.V. Safonova (1986). Methodological possibilities of teaching a foreign language were offered by I.Y. Krivobokova, T.V. Lotareva (1989), L.N. Pustosmehova (1999), N.N. Trubaneva (1994).

\subsection{Hypothesis}

The analysis of theoretical studies and practical activities in the aspect of the problem studied showed that the success of early foreign-language education in an elementary school is possible provided that the following conditions are met:

- The basic components of teaching foreign languages in primary school (linguistic, psychological, methodological components) are provided;

- The most important social and pedagogical functions of the methodical system of foreign language education in primary school are realized (developing, educational, development of communicative competence, development of memory, thinking and creative abilities);

- Opportunities to improve the skills of foreign-language speech activity in the conditions of early foreign-language education are revealed;

- The main aspects of the organization of early foreign-language education are defined;

- The constant introduction of younger schoolchildren to a new language space for them is ensured;

- A positive attitude towards further study of a foreign language is formed in younger schoolchildren.

\section{Materials and Methods}

\subsection{The Tasks of the Research}

In this study, the following tasks were set: 1) To analyze the features and advantages of early foreign-language education; 2) To identify opportunities for improving the skills of foreign-language speech activity in the conditions of early foreign-language education; 3) To develop the main sections of the organization of early foreign-

XLinguae, Volume 11, Issue 2, April 2018, ISSN 1337-8384, eISSN 2453-711X 
language education in a functional context; 4) To determine the main aspects of the organization of early foreign-language education; 5) To study the main components of teaching foreign languages in the elementary school (linguistic, psychological, methodological).

\subsection{Theoretical and Empirical Methods}

To test the hypothesis, various methods were used, complementing each other: A theoretical analysis of psychological-pedagogical and methodical literature; Generalization of pedagogical experience; The analysis of programs and manuals on a foreign language; Questioning, interviewing, pedagogical observation; Self-esteem by junior schoolchildren of the level of development of their linguistic abilities; Conversations, written and oral interviews, testing of junior schoolchildren; Pedagogical experiment; Analysis of the results of the search activity.

\subsection{The Trial Infrastructure and Stages of the Research}

The basis of the study was the Municipal Budget Educational Establishment "Gymnasium No. 155 with the Tatar language of instruction" of the Novo-Savinovsky District of Kazan. The study was conducted within the framework of teaching junior students in the academic discipline "Foreign Language". The study was conducted in two stages:

At the first stage (September 2016), young schoolchildren were introduced to a new language space for them in order to develop their ability to recognize and differentiate linguistic phenomena and words in a foreign language; Providing the basic components of teaching a foreign language (linguistic, psychological, methodological) with the aim of forming intellectual and cognitive abilities among younger schoolchildren, and hence - increasing the motivation to further study the English language. The state of this problem was studied in the scientific literature and educational practice; The empirical material was collected; The nature of students' relationships with the problems of developing listening and speaking skills, as well as the development of the ability to observe this or that linguistic phenomenon in the perceived speech of the teacher was examined.

At the second stage (May 2017) a system was developed to explore the advantages of early foreign-language education; An experimental verification of the effectiveness of the organization of improving the skills of foreign-language speech activity in the conditions of early foreign-language education, as well as the possibilities of their direction on the development of the language personality was led; the registration of research results was led.

\subsection{Organization of Early Foreign Language Education in a Functional Context}

Analysis of the organization of early foreign-language education in a functional context led us to identify the most important socio-pedagogical functions of the methodological system of foreign-language education in primary school, which are aimed at meeting the needs of the younger schoolchild's personality. The main of these functions are developing and educational. So, the developing function is the development and self-development of the younger schoolchild's personality and his creative potential in the process of mastering the foreign language; development of his speech ability, social development, etc. This should contribute to the acquisition of the child cultural and moral values in the national and universal understanding. As for the educational function of teaching a foreign language, it is aimed at ensuring the moral development of a growing person as a subject of one's culture, capable of (at the most elementary level) multicultural communication in a foreign language, and also as a subject of a culture of educational work capable of productive cognitive activity on mastering a foreign language. Thus, in the center of the methodical system is the 
student as the subject of learning and culture, capable of actualizing his cognitive activity and creativity.

The next important function of teaching a foreign language in an elementary school is the development of the communicative competence of schoolchildren, i.e. training in the use of, for example, English as a means of communication. To successfully master a foreign language, students must know the language forms (grammar and vocabulary), be able to use them for real communication and have an idea of the culture of the language being studied. This function of a foreign language as a school subject is, therefore, in the development of the general speech ability of a schoolchild in his most elementary philological education; and also in the formation of abilities and readiness to use just a foreign language as a means of communication as a way of getting involved in another national culture. This function of the subject should be implemented from the first steps of schooling.

An important function, as it seems to us, is the development of memory, thinking and creative abilities in the child by means of the English language, which is formulated as the formation of universal educational activities that ensure the ability to learn, the ability to work independently and self-development (Asmolov, Burmenskaya, Volodarskaya, 2008).

So, the process of foreign language education actually includes such aspects as: 1) knowledge: it is aimed at mastering the cultural content of a foreign culture (this includes not only the culture of the country but also language as a part of culture); 2) development: it is aimed at mastering the psychological content of foreign culture (abilities, mental functions, etc.); 3) upbringing: it is aimed at mastering foreign culture in terms of moral and ethical aspects; 4) teaching: it is aimed at mastering the social content of a culture speaking another language from the point of view that speech skills are assimilated as means of communication in the society. In this connection, when we are talking about the practical purpose of a foreign language we mean not only the realization of these functions but also the realization of a practical result, i.e. mastering a junior schoolchild with speech skills. And this means mastering the cultural and psychological aspects of the content of foreign language culture precisely in the process of mastering these aspects "here and now" and not after that.

\subsection{The Advantage of Early Foreign Language Education}

Early foreign-language education has many advantages, some of which seem to us to be the most important. So, the positive role of early learning for foreign languages is as follows:

- Teaching junior schoolchildren a foreign language contributes to the development of their mental processes necessary for the formation of language abilities (stability of attention, memory, thinking), including communication skills;

- Creates the prerequisites for the formation of interest in other cultures;

- Promotes self-identification of the child's personality;

- Promotes the socialization of the child's personality through active interaction with peers and communication with adults in order to achieve mutual understanding;

- Contributes to the development of emotional-volitional qualities of the child through overcoming obstacles in achieving the goal, the desire to adequately assess the results of their actions;

- Contributes to the improvement of all native speech parties as well by expanding their vocabulary.

Proceeding from this, the following prerequisites are created for successful mastering of a foreign language at a younger school age:

- The ability to maintain a sustained attention when performing tasks;

- The predominance of the imagination, and hence the development of imaginative thinking;

XLinguae, Volume 11, Issue 2, April 2018, ISSN 1337-8384, eISSN 2453-711X 
- Ability to target memorization of the proposed information;

- Expansion of thinking activity;

- The beginning of the formation of the process of logical thinking;

- The formation of the ability to initial forms of generalization and inference;

- Laying the foundation for conceptual thinking;

- An increase in the level of mental development;

- The emergence of a clearer awareness of what is useful or harmful;

- Intensive formation of cognitive needs and craving for new knowledge.

On the basis of this, the following goals are realized in the primary school:

- Constant familiarization of younger school students with a new language space for them and the formation of a positive attitude towards further study of a foreign language;

- Formation of elementary communicative skills in four types of speech activity (speaking, listening, reading, writing), taking into account the speech capabilities and needs of junior schoolchildren;

- Familiarization of junior schoolchildren with the world of foreign peers, with foreign music and literature with accessible to them art samples in the studied language.

Thus, based on the advantages of systematic teaching children a foreign language at a younger school age, it can be noted that learning a foreign language at a given age is beneficial to all children, regardless of their starting abilities.

\section{Results}

\subsection{Possibilities for Improving the Skills of Foreign-Language Speech Activity in the Conditions of Early Foreign-Language Education}

The process of forming the skills of foreign speech activity is a process of forming an integral speech mechanism. Therefore, the opportunities for improving the skills of foreign-language speech activity in the conditions of early foreign-language education are associated precisely with the formation of the speech mechanism as a process of personal development. Indeed, the results of speech activity, one way or another, are always directed at the social needs of the individual, i.e. on the possibility of successful communication in the society, especially in a multicultural environment. Proceeding from this, the basis of skills of a speech orientation is laid down the following: Planning of the statement, using verbal means and their semantic maintenance; Expression of one's thoughts with an adequate use of the stock of linguistic means; Observance of the culture of communication in speech and nonverbal behavior in the address to the interlocutor, etc. All this determines the specific goals of teaching younger pupils to a foreign language, for example: The formation and development of foreign phonetic skills; Development of listening skills (understanding of speech by ear); Development of skills of "speaking" (i.e. formation of the idea of a foreign language as a means of communication); Formation and replenishment of lexical stock.

For example, work on the formation of phonetic skills is usually carried out during a special stage of the lesson: phonetic charging. And when studying vocabulary it is important that any input word is communicatively meaningful for the child, and also enter into semantic and grammatical links with other words (for example: Not acquaintance with isolated words but with groups of words related to semantic or phonetic association; The inclusion of new words in the system of relations that has already developed between the well-known children's words; When acquainted with the lexical material and grammatical rules all this is introduced into speech activity). As for listening it is a difficult activity for students. Therefore, in order to be the most successful in listening to primary classes the material presented should be feasible, short-lived and meet the interests of students of this age. It is important to develop listening skills in parallel with auditory memory and auditory perception. The main thing is that listening skills (or understanding of speech) should be developed and 
fixed in the process of communication between the teacher and children in a foreign language, i.e. explanations, instructions, requests, comments, and assessments should be used in a foreign language. In the sphere of speaking it is necessary to create a situation of dialogical communication at an elementary level; to help children create elementary coherent statements about themselves and the world around them, about what they read, seen, heard, while expressing at an elementary level their attitude to the perceived information or the subject of the utterance. Therefore, it is necessary to carefully select and dose the communicatively valuable speech material for a given age. And the very method of working in the lesson should be organized in such a way that the student does the job not on duty, but on the basis of an interest in communicating with the teacher and his peers.

\subsection{The Procedure and Results of the Experiment}

Organizing in the course of the experimental work the cognitive process of younger schoolchildren in the direction of the formation of intellectual and cognitive abilities in them (taking into account the development of the potential in the study of a foreign language) there was identified the students' level of motivation for further study of the English language. We proceeded from the assumption that younger schoolchildren should form elementary communicative skills in listening and speaking, as well as the ability to analyze and generalize linguistic phenomena in foreign and native languages. At the same time, the indicators of younger potential students in the study of a foreign language suggest the development of their ability to correctly perceive a linguistic phenomenon in a foreign language and the ability to differentiate them. Therefore, at the diagnostic stage, students developed the following ideas: On the possibilities of developing the ability to perceive foreign words; The formation of importance of listening to the teacher and interlocutor; The formation of need to penetrate the culture of another people; The formation of prospects of developing the skill of working in different modes (individually, in pairs, in front, in a group), interacting with each other; The formation of importance of developing the ability to observe this or that linguistic phenomenon in the perceived speech of the teacher; The formation of need to develop the ability to highlight the main thing when listening to a speech expression, etc. In this regard, we focused on the use of various tests that process such basic groups of exercises as: a survey test; test for knowledge of grammar; test for the stock of words; test on the ability to work with texts; audio testing, etc. Work on the development components of junior high school students in the study of a foreign language was conducted in the 2016-2017 academic year: initially in September 2016, again in May 2017 in one experimental and one control group. The control group included 24 students of $2^{\text {nd }}$ form of Gymnasium No. 155 with Tatar language of instruction in Kazan, who study Tatar as the main subject and English as an additional subject; the experimental group consisted of 22 students of the 3rd form of the school, who study English as the main subject along with the Tatar language. The results of the diagnosis are shown in Table 1.

Table 1: Development of the potential in the study of a foreign language for junior schoolchildren ("Plus" means an increase in indicators in \% for the period September 2016 - May 2017)

\begin{tabular}{|l|l|l|}
\hline $\begin{array}{l}\text { Developmental components of } \\
\text { junior high school students in } \\
\text { learning a foreign language }\end{array}$ & $\begin{array}{l}\text { Control group } \\
\text { (studying Tatar as the } \\
\text { main subject and } \\
\text { English as an } \\
\text { additional subject) }\end{array}$ & $\begin{array}{l}\text { Experimental group } \\
\text { (studying the English } \\
\text { language as the main } \\
\text { subject along with the } \\
\text { Tatar language) }\end{array}$ \\
\hline $\begin{array}{l}\text { Ability to correctly perceive a } \\
\text { linguistic phenomenon in a }\end{array}$ & $+5 \%$ & $+43 \%$ \\
\hline
\end{tabular}

XLinguae, Volume 11, Issue 2, April 2018, ISSN 1337-8384, eISSN 2453-711X 


\begin{tabular}{|l|l|l|}
\hline foreign language & & $+21 \%$ \\
\hline $\begin{array}{l}\text { The ability to differentiate } \\
\text { language phenomena in a foreign } \\
\text { language }\end{array}$ & $+2 \%$ & $+18 \%$ \\
\hline $\begin{array}{l}\text { Development of the ability to } \\
\text { analyze and generalize linguistic } \\
\text { phenomena in foreign and native } \\
\text { languages }\end{array}$ & $+1 \%$ & $+38 \%$ \\
\hline $\begin{array}{l}\text { Formation of elementary } \\
\text { communicative skills in listening }\end{array}$ & $+1 \%$ & $+45 \%$ \\
\hline $\begin{array}{l}\text { Formation of elementary } \\
\text { communicative skills in speaking }\end{array}$ & $+1 \%$ & $+56 \%$ \\
\hline $\begin{array}{l}\text { Ability to control one's own } \\
\text { speech actions }\end{array}$ & $+6 \%$ & $+44 \%$ \\
\hline $\begin{array}{l}\text { Formation of intellectual and } \\
\text { cognitive abilities }\end{array}$ & $+8 \%$ & $+90 \%$ \\
\hline $\begin{array}{l}\text { Development of motivation for } \\
\text { further study of English }\end{array}$ & $+10 \%$ & \\
\hline
\end{tabular}

Compared with the results of the control group in the experimental group, one can observe a steady growth in all factors. Thus, based on the results of the diagnosis of the totality of questions and assignments made to students with the purpose of qualimetric identification of the linguistic and psychological characteristics of the individual, we observe that the dynamics of the increase in the language level of the students participating in the experiment exceeds the analogous dynamics of the control group. This may indicate the effectiveness of formation in younger students of intellectual and cognitive abilities in the course of experimental work in the conditions of the national school. The dynamics of the indicators of the ability to correctly perceive a linguistic phenomenon in a foreign language indicates the following: Most schoolchildren have increased the dynamics of the development of the ability to differentiate linguistic phenomena in a foreign language; they have intensified the development of the ability to analyze and generalize linguistic phenomena in foreign and native languages; there has been activated the formation of elementary communicative skills among students in listening and speaking; there has been activated the formation of a person who is able at this stage to understand, speak, read, write in the studied language and on this basis the development of his or her thinking and memory. At the same time, the number of schoolchildren with a narrow range of knowledge and communication skills has decreased. All of the foregoing allows us to state that the study confirmed the main provisions of the hypothesis and allowed to increase the level of motivation for further study of the English language. However, this does not solve all the issues related to the provision of psychological and pedagogical conditions for quality education in early foreign-language education in primary school. Further studies require questions of the implementation in various forms of the main aspects of the process of foreign language education: Cognition, development, education, teaching; Self-actualization of students in the process of learning a foreign language; Opportunities for extra-curricular work of students in order to form their readiness for any kind of mental activity, etc.

\section{Discussion}

So, taking into account the understanding of the features of foreign-language education in primary school as a system where a set of educational processes in a foreign language is carried out, the specifics of the functioning of the system of language education as such is determined by the following factors: 
- Socio-economic and political factors (social order of the society in relation to the level and quality of training in a foreign language, which is expressed in the prestige of language learning in the school, in ensuring the choice of the content of training and its methodology);

- Socio-pedagogical factors (conceptual approaches to the content of the academic subject "Foreign Language" and its organization in the context of general education tasks, its place, and status in language education and in an educational institution of a particular type);

- Factors of methodology (provide teaching of a foreign language at school in the categories of methodological science, where specific programs, textbooks, manuals and other methodological materials are presented);

- Sociocultural factors (provide the socio-cultural context of teaching a foreign language, taking into account the commonality or difference in the culture of the country of the language and native culture being studied);

- Individual factors (take into account the individual characteristics of subjects of the educational process, their desires, intentions, interests, plans, their social and cultural orientation, as well as motivation for learning the language).

Practice shows that early learning a foreign language has a great practical effect in terms of improving the quality of first foreign language and further creates a basis for continuing its study in the mainstream school. At the same time, early foreignlanguage education in the conditions of an elementary school opens up opportunities for learning the second, third foreign languages; the necessity of owning them becomes more and more obvious today. It is important to note, in this connection, the educational and informative value of early learning a foreign language which manifests itself in the child's earlier entry into the universal culture through communication in a new language for him. The constant conversion of the child to his experience of perception of reality allows him to better understand the phenomena of his own national culture in comparison with the culture of the country of the studied language. And for this it is necessary that, in the context of methodological continuity, a smooth transition of children from one level of study to another is ensured, thereby avoiding the loss of the formed linguistic skills. That is why it is so important throughout the course of teaching a foreign language to adhere to a unified learning strategy that provides a clear formulation and achievement of the learning objectives of each level in the interaction between them. Such interaction is achieved through cross-cutting programs and the use of benefits that consistently lead the child from primary to secondary school.

\section{Conclusion}

Summing up the above, related to various aspects of early foreign-language education in the conditions of primary school, we came to the following conclusions. Taking into account the fact that the initial foreign language education is a purposeful process of the development and self-development of the personality of the junior schoolchild and his abilities for multicultural communication by controlling the teacher by his teaching activity in mastering a foreign language, the result is the acquisition by the pupil of personal qualities, values and abilities that were not previously. Thus, based on this thesis, the goal and the product of the primary foreign language education is the personality of the junior schoolchild as a set of personal qualities, skills, and skills for communication in a foreign language. And all this are formed in the course of his educational activities. In this regard, the content of teaching a foreign language at an early stage must meet the following requirements:

- The content of teaching a foreign language should correspond to the communicative and cognitive interests of the younger student; The communication and speech material offered at the session should reflect the real conditions for using a foreign

XLinguae, Volume 11, Issue 2, April 2018, ISSN 1337-8384, eISSN 2453-711X 
language and create all the possibilities for influencing the motivational and motivating sphere of the child's personality, developing his imagination, curiosity, and creativity;

- To integrate various types of activities typical for primary school children (visual, musical, stage, etc.) in the foreign language teaching process, thereby creating conditions for the harmonious development of the child's personality;

- To take into account the child's personal experience of communication in his native language and correlate it with the experience he must acquire in the classroom in a foreign language, especially when he must learn to speak, listen and write on it;

- To open the child access to the culture of another people, introducing him to the peculiarities of the everyday life of peers in the country of the studied language (for example, with the traditions of celebrations);

- To arouse the interest of children in the manifestation of their imagination and creativity, as well as to form an ability to interact productively with peers in game situations.

Thus, starting from the first steps in learning a foreign language, children should learn about the culture of the country of the studied language, the life of their peers abroad and the peculiarities of their everyday life. And it is very important that early learning a foreign language corresponds to the internal psychological development of the child, therefore the educational process must be organized in accordance with its agespecific psychological features, so that nothing disturbs the natural course of things, but only activates the opportunities inherent in the child by nature, at each stage of it development.

\section{Acknowledgments}

The work is performed according to the Russian Government Program of Competitive Growth of Kazan Federal University.

Part of the research was funded by the Cultural and Educational Grant Agency of the Ministry of Education, Science, Research and Sport of the Slovak Republic (KEGA 006UKF-4/2017).

This work wassupported by the Slovak Research and Development Agencyunderthecontract No. APVV-15-0368.

\section{Bibliographic references}

ASMOLOV, A.G. - BURMENSKAYA, G.V. - VOLODARSKAYA, I.A. 2008. How to design universal educational activities in a primary school. From action to thought: a manual for the teacher. Moscow: Prosveshchenie. ISBN 978-5-09-019148-7.

BARANNIKOV, A.V. 2002. On the introduction of a foreign language in the II grade of primary school in the conditions of the experiment to update the structure and content of general education in the 2002/2003 school year. In: Foreign languages at school, vol. 2, pp. 4-7. ISSN 0130-6073.

BEZRUKIH, M.M. 2009. Difficulties of teaching in an elementary school: Causes, diagnostics, comprehensive help. Moscow: Eksmo. ISBN 978-5-699-31065-4.

BIBOLETOVA, M.Z. 1985. Teaching the grammatical aspect of speaking in English for pupils of the 1-3 grades of the general education school (at the beginning of the education from the age of six). PhD thesis. Moscow, $163 \mathrm{p}$.

GALSKOVA, N.D. 1990. On the results of the second year of experimental teaching of foreign languages in primary school. In: Foreign languages in school, vol. 1, pp. 15-17. ISSN 0130-6073.

GORLOVA, N.A. 2010. The state of the methodology of early learning of foreign languages on the threshold of the third millennium. In: Foreign languages in school, vol. 5, pp. 25-29. ISSN 0130-6073. 
GRISHANOVA, I.A. 2007. Actualization of the situation of success in teaching a foreign language to junior schoolchildren. In: Foreign languages in school, vol. 8, pp. 28-30. ISSN 0130-6073.

DENISENKO, O.A. 1995. Technique of early learning of English on the basis of works of English literature: $\mathrm{PhD}$ thesis. Tambov, $157 \mathrm{p}$.

ELUKHINA, N.V. 1986. Intensification of the teaching of listening at the initial stage. In: Foreign languages in school, vol. 5, pp. 15-20. ISSN 0130-6073.

IVANOVA, E.G. 2003. Method of training in cooperation at the initial stage of the secondary school: $\mathrm{PhD}$ thesis. Moscow, $161 \mathrm{p}$.

KASPAROVA, M.G. 1986. On some components of foreign abilities and their development in schoolchildren. In: Foreign languages in school, vol. 5, pp. 18-26. ISSN 0130-6073.

KOROSTELEV, V.S. 1992. Learning foreign-language communication at the initial stage. In: Foreign languages in school, vol. 1, pp. 44-46. ISSN 0130-6073.

KRIVOBOKOV, I.Y. - LOTAREVA, T.V. 1989. Some methods of teaching English at the primary stage. In: Foreign languages in school, vol. 1, pp. 52-54. ISSN 01306073.

LOGUNOVA, S.V. 1997. The method of forming grammatical constructing skills in the early learning of the English language: $\mathrm{PhD}$ thesis. Tambov, $162 \mathrm{p}$.

LOMAKINA, G.R. 2014. Early Learning a Foreign Language: the Pros and Cons. In: Young Scientist, vol. 20, pp. 597-599. ISSN 2072-0297.

NASIBULLOV, R.R. - NEYASOVA, I.A., ADILOVA, V.K., 2016. Diagnostics of elementary school children social representations, concepts, knowledge development level. In: International Journal of Environmental and Science Education, vol. 11, n. 3, pp. 299-308. ISSN 1306-3065.

NEGNEVITSKAYA, E.I. 1987. Foreign language for the youngest: yesterday, today, tomorrow. In: Foreign languages at school, vol. 6, pp. 20-26. ISSN 0130-6073.

NEGNEVITSKAYA, E.I. 1986. Psychological conditions of the formation of speech skills and skills in preschool children in the second language: $\mathrm{PhD}$ thesis. Moscow, $159 \mathrm{p}$.

NIKITENKO, Z.N. 2008. Creation of a cultural environment for the education of junior schoolchildren. In: Foreign languages at school, vol. 4, pp. 11-15. ISSN 01306073.

PALMER, H.E. 1923. The Oral Method of Teaching Languages. A monograph on conversational methods together with a full description and numerous examples of 50 appropriate forms of work. Cambridge: Cambridge Press, $164 \mathrm{p}$.

PIROZHKOVA, A.O. 2014. Teaching English language of junior schoolchildren taking into account their psychological features. In: Problems of Modern Pedagogical Education, vol. 44, pp. 199-207. ISSN: 2311-1305.

PLIGIN, A.A. 2008. Purposeful development of cognitive strategies in English classes. In: Foreign languages in school, vol. 3, pp, 12-19. ISSN 0130-6073.

PUSTOSMEHOVA, L.N. 1999. Features of the organization of a role-playing game based on television programs in teaching a foreign language at different stages of training: $\mathrm{PhD}$ thesis. Moscow, $162 \mathrm{p}$.

SALITE, I. 2008. Educational action research for sustainability: Constructing a vision for the future in teacher education. In: Journal of Teacher Education for Sustainability, vol. 10, pp. 5-16. ISSN 1691-4147.

SALITE, I. - DRELINGA, E. - ILISKO, D. - OLEHNOVICA, E. - ZARINA, S. 2016. Sustainability from the transdisciplinary perspective: An action research strategy for continuing education program development. In: Journal of Teacher Education for Sustainability, vol. 18, n. 2, pp. 135-152. ISSN 1691-4147.

SHAFIKOVA, A.V. 1998. Multicultural approach in the education and upbringing of schoolchildren: PhD thesis. Kazan: Kazan State University, 193 p.

XLinguae, Volume 11, Issue 2, April 2018, ISSN 1337-8384, eISSN 2453-711X 
SAFONOVA, I.V. 1986. Education of junior schoolchildren relevant to the speech practice of coherent statements: $\mathrm{PhD}$ thesis. Moscow, $160 \mathrm{p}$.

TRUBANEVA, N.N. 1994. English language training in the framework of the integrated course "English Language and the World": PhD thesis. Moscow, 163 p.

TSYBAN, L.A. 2017. Problems of teaching a foreign language in an elementary school. In: Young Scientist, vol. 7, pp. 506-509. ISSN 2072-0297.

VALEEV, A.A. - MUZAFAROVA, N.M. 2016. Actualization of the supessoric approach in teaching a foreign language. Actual problems of pedagogy and psychology. Kazan: Publishing house "Otechestvo". pp. 71-75. ISBN 978-5-92221132-1.

VERESHCHAGINA, I.N. - ROGOVA, G.V. 1998. Methodology of teaching English at the initial stage in general education institutions. Moscow: "Prosveshchenie". ISBN 5-09-001029-3.

VERESHCHAGINA, I.N. - ROGOVA, G.V. 1999. Book for the teacher to the textbook of English for the 2nd form of schools with in-depth study of the English language. Moscow: Prosveshchenie. ISBN 5-09-001029-3.

VYATYUTNEV, M.N. 1990. Teaching a foreign language in an elementary school. In: Foreign languages in school, vol. 6, pp. 35-37. ISSN 0130-6073.

Words: 6944

Characters: 45587 (25,33 standard pages)

Anvar N. Khuziakhmetov

Department of Methodology of Teaching and Upbringing,

Institute of Psychology and Education

Kazan (Volga region) Federal University

18 Kremlyovskaya Str. 420008, Kazan

Russia

hanvar9999@mail.ru

Agzam A. Valeev

Department of Foreign Languages for Natural Sciences

Institute of International Relations, History and Oriental Studies

Kazan (Volga region) Federal University

18 Kremlyovskaya Str. 420008, Kazan

Russia

agzam.valeev1952@yandex.ru

Zdena Kralova

Department of Language Pedagogy and Intercultural Studies

Faculty of Education

Constantine the Philosopher University in Nitra

Drazovska cesta 4, 94974 Nitra

Slovakia

zkralova@ukf.sk

Jana Duchovicova

Department of Pedagogy, Faculty of Education

Constantine the Philosopher University in Nitra,

Drazovska cesta 4,949 74 Nitra,

Slovakia

jduchovicova@ukf.sk 